\title{
ELECTRICAL DISCHARGE MACHINING OF CERAMIC/SEMICONDUCTOR/METAL NANOCOMPOSITES
}

\author{
S. Lopez-Esteban ${ }^{1}$, C.F. Gutierrez-Gonzalez ${ }^{1}$, G. Mata-Osoro ${ }^{2}$, \\ C. Pecharroman ${ }^{2}$, L.A. Diaz ${ }^{1}$, R. Torrecillas ${ }^{1}$, J.S. Moya ${ }^{2}$ \\ ${ }^{1}$ Centro de Investigación en Nanomateriales y Nanotecnología (CINN) [Consejo Superior de \\ Investigaciones Científicas (CSIC)-Universidad de Oviedo (UO)-Principado de Asturias (PA)]; \\ Parque Tecnológico de Asturias, 33428 Llanera (Spain). \\ ${ }^{2}$ Instituto de Ciencia de Materiales de Madrid, Consejo Superior de Investigaciones Científicas \\ (ICMM-CSIC), Cantoblanco, 28049 Madrid (Spain). \\ *Corresponding author to whom all the correspondence should be addressed. E-mail: \\ s.lopez@cinn.es, Tel.: +34-985.980.058, Fax: +34-985.265.574
}

\begin{abstract}
:
Electroconductive, homogeneous and dense ceramic/semiconductor/metal nanocomposites were obtained by hot press and subsequently machined by wire Electrical Discharge Machining (EDM). The addition of semiconductor and metal phases to a highperformance ceramic material produces nanocomposites which preserve the excellent mechanical properties of the ceramic/metal material while reaching the electrical conductivity necessary for EDM. The role of the low concentration of metal has been investigated from a mechanical and an electrical point of view resulting critical for the final behaviour.
\end{abstract}

Keywords: Hot pressing; Electrical resistivity/conductivity; Mechanical properties testing; Nanocomposite; EDM (Electrical Discharge Machining).

Finishing advanced ceramic materials into intricate shapes with the required tolerance is often extremely difficult using traditional machining methods. This fact is even critical in case of hard and superhard materials. This has led to the development of more sophisticated machining methods which do not depend on mechanical contact. Electrical Discharge Machining $(E D M)$ is such a technique, and it successfully overcomes many of the difficulties 
faced by other techniques avoiding the expensive grinding operation for final shaping and surface finishing of components [1]. EDM is based on the material erosion of electrically conductive materials. It is given through series of spatially discrete high-frequency electrical discharges (sparks) between tool and work piece. The fact that EDM does not involve any physical contact between electrodes points it out as a unique shaping procedure for hard, brittle and refractory materials. There are a few material requirements, such as a minimum electrical conductivity: EDM can be successfully applied to single-phase ceramics, cermets, and ceramic/matrix composites, as far as they exhibit an electrical resistivity lower than values between 100 and $300 \Omega \cdot \mathrm{cm}$ [2]. EDM achieves high removal rates as compared with traditional techniques for the machining of these materials. For machinable materials, very good tolerances of below $1 \mu \mathrm{m}$ have been achieved while reducing important machining costs.

Research has successfully demonstrated that ceramics such as $\mathrm{TiB}_{2}, \mathrm{~B}_{4} \mathrm{C}$, and several composites containing nitrides, carbides, and borides can be shaped to an ultra-smooth finish. On the other hand, $\mathrm{TiN}, \mathrm{TiC}, \mathrm{Ti}(\mathrm{C}, \mathrm{N})$ have been considered to be conductive phases in the electroconductive ceramic composites. Therefore, by adding a transition metal carbide to a high-performance ceramic material, a composite can be produced combining the good electrical conductivity of the carbide with the high strength and wear resistance of the matrix [3]. In the case of zirconia matrix, a successful approach is to incorporate electrically conductive reinforcements such as $\mathrm{TiC}$ [4], $\mathrm{TiB}_{2}$, TiN, [5,6], $\mathrm{WC}[4,7], \mathrm{ZrB}_{2}[8], \mathrm{TiCN}$ [4] and $\mathrm{TiN}[6,9]$.

Nowadays, it has been deservedly emphasized in the literature the technological importance of nanostructured composite materials formed by metallic nanoparticles dispersed within a ceramic matrix $[10,11,12]$. The synergistic effect of the nanometer particle size, the clusters and the ceramic/metal interfaces produces an unexpected enhancement in the hardness. As a consequence, nanocomposites exhibit exceptionally high hardness when compared with current commercial materials and, therefore, are extremely difficult to machine by traditional 
methods. Various electro-conductive phases can be added to tune the electrical properties with the aim of turning these materials into machinable by EDM -while keeping their mechanical features-. Thus, this is the main goal of this work focused on ceramic/semiconductor/metal nanocomposites.

The following commercially available powders have been used as raw materials: (1) Tetragonal zirconia polycrystals (3Y-TZP, 3 mol\% $\mathrm{Y}_{2} \mathrm{O}_{3} ;$ TZ-3YE, Tosoh Corp.), with an average particle size of $d_{50}=0.26 \pm 0.05$ microns; (2) nickel (II) nitrate hexahydrate (Merck, Germany, $99.0 \%$ purity, $\mathrm{Ni}\left(\mathrm{NO}_{3}\right)_{2} \cdot 6 \mathrm{H}_{2} \mathrm{O}$ ); (3) nanosized titanium carbide (nTiC, Hubei Minmetals, China). Two sets of composites have been obtained: $3 \mathrm{Y}-\mathrm{TZP} / \mathrm{nTiC} / \mathrm{nNi}$ and $3 \mathrm{Y}-$ $\mathrm{TZP} / \mathrm{nTiC}$. The corresponding powders were processed as follows:

a) $\underline{3 Y-T Z P / n T i C / n N i}(Z T N)$ powder has been obtained starting from the ceramic/metal powder, 3Y-TZP/nNi, which has been prepared by deposition of nickel nanoparticles on the surface of the ceramic powders [13]. Nickel nitrate salt powders were dispersed in absolute alcohol by ultrasonic agitation in a suitable volume of alcohol to achieve total dilution. The ceramic powder was then added and the suspension was milled for $24 \mathrm{~h}$ with zirconia balls. The mixture was dried at $115^{\circ} \mathrm{C}$ and then calcined at $600^{\circ} \mathrm{C}$ for 2 hours in air to obtain $\mathrm{ZrO}_{2} / \mathrm{NiO}$ powders . Next, 20 vol\% nTiC was added to the resulting powder and mixed for 2 hours by attrition milling. After drying and sieving down to $100 \mu \mathrm{m}$, the $\mathrm{NiO}$ was reduced to metallic nickel in a $90 \% \mathrm{Ar} / 10 \% \mathrm{H}_{2}$ atmosphere at $500^{\circ} \mathrm{C}$ for 2 hours, obtaining zirconia/nTiC/nNi (ZTN). The resultant composition was: 72 vol\% $\mathrm{ZrO}_{2}, 20$ vol\% nTiC and 8 vol\% nNi.

b) $\underline{3 Y-T Z P / n T i C}(\mathrm{ZT})$ powder (28 vol\% nTiC) has been prepared by mixing the corresponding starting powders in attrition milling in distilled water for one hour. Afterwards, the powder was dried and sieved down to $100 \mu \mathrm{m}$. 
X- ray diffraction analysis of nanopowders at different stages of the processing route was used for phase identification (XRD Bruker AXS D8 ADVANCE, with a SolX energydispersive detector).

Powders of both nanocomposites were sintered by hot press (HP, HPW 150/200-2200100AS, KCE, Germany). The disks were hot-pressed in a carbon die of $50 \mathrm{~mm}$ diameter in argon atmosphere at $1400^{\circ} \mathrm{C}, 10^{\circ} \mathrm{C} / \mathrm{min}, 25 \mathrm{MPa}$ for 1 hour. Likewise, a pure zirconia disk was prepared for comparison purposes. The density of the sintered samples was measured in distilled water, according to the Archimedes method (LA120S Analytical balance, Sartorius $A G$, Germany). The microstructure of the different samples was characterized with a scanning electron microscope (SEM) Zeiss DSM 942, equipped with Energy Dispersive X-ray microanalyzer (EDX) Link. Field Emission Scanning Electro Microscopy studies were performed using a Carl Zeiss Ultra Plus FE-SEM. Likewise, the microstructure was studied on a Jeol-JEM-2010 (at $200 \mathrm{kV}$ ) Transmission Electron Microscope (TEM) equipped with EDX Oxford-Link Pentafet.

The disks sintered by hot-press that presented an electrical resistivity under the required limit $(\rho=100-300 \Omega \cdot \mathrm{cm})$ were machined by Wire Electric Discharge Machine (Wire EDM). All wire EDM experiments have been performed on a commercial machine (AGIE model 100D, Wire Electric Discharge Machine, WEDM). The brass wire electrodes used have been commercial (Tecfil, Thermo A, $0.25 \mathrm{~mm}$ diameter). The dielectric fluid was deionized water with a conductivity of 10 micro-siemens. The working conditions were: voltage $270 \mathrm{~V}$ and intensity $0.05 \mathrm{~A}$. The prismatic bars obtained from the disks had $5 \mathrm{~mm}$ width, $3 \mathrm{~mm}$ depth and variable length.

The electrical resistances of the samples were measured with a four-wire (Kelvin) connection method using a separate current source (Keithley 6220, Cleveland, Ohio, USA) and a two-channel nanovoltmeter (Keithley 2182A, Cleveland, Ohio, USA). 
The Vickers hardness $\left(H_{V}\right)$ was measured using a Vickers diamond indenter (Leco 100-A, St. Joseph, MI) on polished surfaces, with applied loads between 9.8 and 294 N. The corresponding indentation sizes were determined using an optical microscope (Leica DMRM, Cambridge, UK). The toughness $\left(K_{I C}\right)$ was calculated from the length of the radial cracks obtained from Vickers indentations.

The bending strength, $\sigma_{f}$, was determined by a three-point bending test using prismatic bars cut out from the previously fired pieces to approximately $4 \mathrm{~mm}$ width, $45 \mathrm{~mm}$ length and $3 \mathrm{~mm}$ thickness. The tensile surface was polished down to $1 \mu \mathrm{m}$. The tests were performed at room temperature using a universal testing machine (Instron Model 4411, Boston, MA). The specimens were loaded to failure with a cross-head speed of $0.5 \mathrm{~mm} / \mathrm{min}$ and a span of $40 \mathrm{~mm}$. Reported strengths represent the mean and standard deviation of at least 10 specimens, and were calculated according the equation (1):

$$
\sigma_{f}=\frac{3 Q L}{2 l h^{2}}
$$

where $Q$ is the failure load, $L$ is the span, $l$ is the width and $h$ is the height.

The starting titanium carbide powder was characterized by TEM, presenting an average particle size under $50 \mathrm{~nm}$. Figure 1 shows the x-ray diffractograms of the powder nanocomposites in the $2 \theta$ range from $5^{\circ}$ to $80^{\circ}$ obtained at different stages of the processing route. The results confirm that products at the first stage consisted only of zirconia and nickel nitrate with no presence of any other phases (Figure 1a). After calcination, the nickel nitrate was oxidized into $\mathrm{NiO}$ and the $\mathrm{TiC}$ nanopowder was added (Figure 1b). No presence of either nickel nitrate or nickel oxide was detected in the final powder, which consisted only of zirconia/nTiC/nNi (Figure 1c).

All the samples reached a relatively high densification degree ( $>98 \%$ of the theoretical densities) after hot pressing at $1400^{\circ} \mathrm{C}$ for 1 hour (Table 1). Homogeneous microstructures of ZTN and ZT were obtained, indicating that the powder mixing procedure followed was 
appropriate. The SEM microstructures of the ZTN sintered samples revealed that nickel and titanium carbide particles appeared homogeneously and well dispersed in the zirconia matrix (Figure 2A). This figure illustrates the three phases identified by EDX: bright grains correspond to zirconia matrix, black grains are titanium carbide, and gray grains correspond to nickel. The $\mathrm{Ni}$ and $\mathrm{TiC}$ particles are randomly distributed within the zirconia matrix. The individual metal and semiconductor particles, however, were mainly present as small agglomerates in the composites (1-2 microns in size), as indicated in Figure 2A by the arrows identified with the number 1. Close observations reveal that a significant amount of individual separated nanoparticles are dispersed in the $\mathrm{ZrO}_{2}$ matrix (identified in the same figure by arrows number 2). SEM micrographs of the fracture surface of the ZTN composite revealed that the grain size of zirconia is far below 1 micron, and the fracture mechanism of the composite was mainly intergranular (Figure 2B). It has been observed that zirconia grain size stays in the submicron range even in the sintered body. This fact is shown in the insert (Figure 2C), which corresponds to an FE-SEM micrograph of a thermally etched surface, where the grain boundaries of zirconia have been revealed.

As shown in Figure 3, the TiC grains do not match the surfaces of the grains around them. This fact has been attributed to the sintering conditions used in the experiment (hot press, $1400^{\circ} \mathrm{C}, 10^{\circ} \mathrm{C} / \mathrm{min}, 25 \mathrm{MPa}$ for 1 hour). The temperature used is far too low for $\mathrm{TiC}$, as temperatures above $2000^{\circ} \mathrm{C}$ are required for sintering this carbide. This behavior may justify the slight drop found in the density of ZT with respect to pure zirconia (Table 1). Other systems described in the literature show that the porosity increases with the second-phase content (nitrides, carbides, etc.) [9,14]. In our case, Ni nanoparticles flow under high pressure and temperature, filling the pores. In this regard, we reached densities as high as $99.1 \%$ th., which, to the best of our knowledge, are the largest ones obtained in composites containing TiC. 
As shown in Table 1, the Vickers hardness increases with respect to pure zirconia (11 GPa) when adding TiC (13.8 GPa for the ZT composites). However, it decreases in ZTN (11.5 $\mathrm{GPa}$ ) as the metal is added, as expected.

Regarding the flexural strength and fracture toughness, Table 1 shows that the nickelfree composites $(\mathrm{ZT})$ present significant lower values than ZTN composites, even lower than those of pure zirconia. Thus, ZTN samples presented a fracture toughness as high as $6.0 \pm 0.2$ $\mathrm{MPa} \cdot \mathrm{m}^{1 / 2}$, while ZT showed 4.5 $\pm 0.2 \mathrm{MPa} \cdot \mathrm{m}^{1 / 2}$. Regarding the flexural strength, ZTN presented $804 \pm 21 \mathrm{MPa}$ while ZT showed only $727 \pm 15 \mathrm{MPa}$. Therefore, it might be assumed that the Ni metal particles play a crucial role in this improvement in mechanical properties. Specifically, these results have been attributed to the excellent interface between zirconia and $\mathrm{Ni}$-which has been thoroughly studied by the authors before, both experimentally (HRTEM studies) and through ab initio simulations [15]-. According to these results, it is well known that $\mathrm{Ni} / \mathrm{ZrO}_{2}$ interfaces present a good epitaxy and display practically no porosity, contributing to reach high densities in the ZTN material (99.1\% th).

The machined surface has been analyzed by FE-SEM/EDS and XRD. Figure 4 shows ZTN nanocomposites machined by EDM as quadrangular prisms (Figure 4A), the surface machined (Figure 4B) and a SEM micrograph of the polished cross section of the cut (Figure 4C). XRD has been performed on the surface machined (Figures 4D and 4E), showing that the composition is zirconia, titanium carbide, metallic nickel and nickel oxide (NiO). This oxide should correspond to the metallic particles exposed during the EDM process. However, even though this oxide may have increased the value of resistivity of the bulk material, it has been still low enough to machine the material because, in fact, it has also been found the coexistence of metallic Ni.

The electrical resistivity of the samples was $14.0 \cdot 10^{-4} \Omega \cdot \mathrm{cm}$, for ZT, and $7.2 \cdot 10^{-4} \Omega \cdot \mathrm{cm}$, for ZTN (Table 1). Thus, the addition of a small amount of metal ( 8 vol\%) decreases the 
resistivity of the composite around 50\%. Although the electrical resistivity of ZT was lower than $100 \Omega \cdot \mathrm{cm}$, which is the maximum required for EDM, this sample was not machinable by this technique, unlike the sample ZTN. Therefore, the addition of a small amount of metal confers the material the capacity to be machinable by EDM, while the mechanical properties (hardness, toughness, flexural strength) have been improved with respect to those of pure zirconia.

The metal nanoparticles seem to play a crucial role in this behavior. Electric discharge machining is a manufacturing process whereby a wanted shape of an object -called workpieceis obtained using electrical discharges. The material removal from the workpiece occurs by a series of rapidly recurring current discharges between two electrodes, separated by a dielectric liquid and subject to an electric voltage. One of the electrodes is the tool, whereas the other is the workpiece. When the distance between the two electrodes is reduced, the intensity of the electric field in the volume between the electrodes is expected to become larger than the dielectric strength -at least in certain points- and therefore a discharge flows between the two electrodes. Once the discharge starts, it forms a plasma in the neighborhood of the machined front (cross section showed in Figure 4B, and front surface showed in Figure 4D).

At this point, two different explanations about how nickel helps in the EDM process are proposed. The first one postulates that plasma is able to fuse and oxidize the material and then, once cooled down, deposits on the fresh surface produced by the cut. This deposit could form a glassy magma constituted by the corresponding oxides. In the particular case of a ceramic/semiconductor composite material, the breakdown voltage of the deposit is higher than the initial. In this scenary, the role of the metal nanoparticles would be to induce a decrease in the breakdown voltage of the layer just deposited, allowing the machining operation in a continuous process. 
The second explanation could be based in the fact that the covalent chemical bond in TiC is considerably stronger than the metallic one in Ni. Therefore, the energy needed to dissociate $\mathrm{Ti}^{4+}$ ions from $\mathrm{TiC}$ is much higher than the ionization potential of $\mathrm{Ni}$. Thus, the addition of $\mathrm{Ni}$ eases the generation of plasma during the discharge process.

Therefore, by adding a semiconductor and a metal to a high-performance ceramic, a composite that combines the good electrical conductivity of both semiconductor and metal, with the high mechanical properties of the matrix can be produced. The metal plays a double role: (a) from the mechanical point of view, the good ceramic/metal interface confers the composite excellent mechanical properties, and (b) from the electrical point of view, nickel confers the machinability by EDM to samples with sufficient low resistivity, which adds plenty of advantages in order to obtain complex shaped components made out of superhard materials. In summary, the results presented in this paper show the excellent properties of ceramic-based oxide/semiconductor/metal nanocomposites and test the possibility of tuning their composition in order to confer the machinability by EDM. It is worthy to point out that ceramic/semiconductor/metal nanocomposites are truly promising materials for a wide range of high-performance applications such as, for instance, inserts for cutting tools or microdevices, among many others. On the other hand, EDM is a this technique that presents multiple advantages with respect to traditional machining methods in order to finish advanced ceramic materials into intricate shapes with the required tolerance while reducing important machining costs.

\section{Acknowledgements}

This research was supported by the European Union under the IP-NANOKER project (FP6-515784-2), by the Spanish Ministry of Education and Science under the project MAT2006-10249-C02-01. 


\section{Figure captions}

Figure 1. X-ray diffractograms of the nanopowders obtained at different stages of the processing route.

Figure 2. (A) Backscattered SEM micrographs of the microstructure of polished ZTN sintered samples. The three phases can be easily differentiated, as bright grains correspond to zirconia matrix, black grains are titanium carbide, and gray grains correspond to nickel. The microstructure reveals that the existence of individual metal and semiconductor particles is mainly present as small agglomerates in the composites (arrows "1"). However, close observations reveal that a significant amount of individual separated nanoparticles are dispersed in the ceramic matrix (arrows "2"). (B) SEM micrograph of the fracture surface of the same composite. (C) FE-SEM micrograph of a thermally etched surface, where the grain boundaries of zirconia have been revealed.

Figure 3. TEM micrograph of the ZTN sintered samples and EDX spectrums corresponding to the $\mathrm{Ni}$ and $\mathrm{TiC}$ particles.

Figure 4. (A) Bars of nanocomposite ZTN machined by EDM. (B) SEM micrograph of the surface machined by EDM. (C) SEM micrograph of the polished cross section of the cut by EDM. Note: the black phase on the machined surface is a shadow of the sample on the resin. (D) XRD of the surface corresponding to Figure 4B. (E) Detail of Figure 4B. 


\section{Table captions}

Table 1. Properties of hot-pressed pure zirconia and composites. 


\section{References}

${ }^{1}$ B. Lauwers, J.P. Kruth, W. Liu, W. Eeraerts, B. Schacht, P. Bleys. J. Mater. Process. Tech. 149 (2004) 347.

${ }^{2}$ W. König, D.F. Dauw, G. Levy, U. Panten. Ann. CIRP 37 (1988) 623.

${ }^{3}$ E. Pippel, J. Woltersdorf. Phys. Status Solidi A. 116 (1989) 165.

${ }^{4}$ B. Lauwers, K. Brans, W. Liu, J. Vleugels, S. Salehi, K. Vanmeensel. CIRP Annals Manufacturing Technology 57 (2008) 191.

${ }^{5}$ C. Sarbu, J. Vleugels, O. Van der Biest. J. Eur. Ceram. Soc. 27 (2007) 2203.

${ }^{6}$ J. Vleugels, O. Van der Biest. J. Am. Ceram. Soc. 82 (1999) 2717.

${ }^{7}$ K. Biswas, A. Mukhopadhyay, B. Basu, K. Chattopadhyay. J. Mater. Res. 22 (2007) 1491.

${ }^{8}$ B. Basu, T. Venkateswaran, D.Y. Kim. J. Am. Ceram. Soc. 89 (2006) 2405.

${ }^{9}$ S. Salehi, O. Van der Biest, J. Vleugels. J. Eur. Ceram. Soc. 26 (2006) 3173.

${ }^{10}$ J.S. Moya, S. Lopez-Esteban, C. Pecharroman. Prog. Mater. Sci. 52 (2007) 1017.

${ }^{11}$ T. Rodriguez-Suarez, L.A. Diaz, R. Torrecillas, S. Lopez-Esteban, W.H. Tuan, M. Nygren, J.S. Moya. Comp. Sci. Tech. 69 (2009) 2467.

${ }^{12}$ R.G. Duan, J.D. Kuntz, J.E. Garay, A.K. Mukherjee. Scripta Mater. 50 (2004) 1309.

${ }^{13}$ F. Esteban-Betegon, S. Lopez-Esteban, J. Requena, C. Pecharroman, J.S. Moya, J.C. Conesa. J. Am. Ceram. Soc. 89 (2006) 144.

${ }^{14}$ S. Ran, L. Gao. J. Am. Ceram. Soc. 90 (2007) 2626.

${ }^{15}$ C. Pecharroman, J.I. Beltran, F. Esteban-Betegon, S. Lopez-Esteban, J.F. Bartolome, M.C. Munoz, J.S. Moya, Z. Metallkd, 96 (2005) 507. 
Figure 1

Click here to download high resolution image

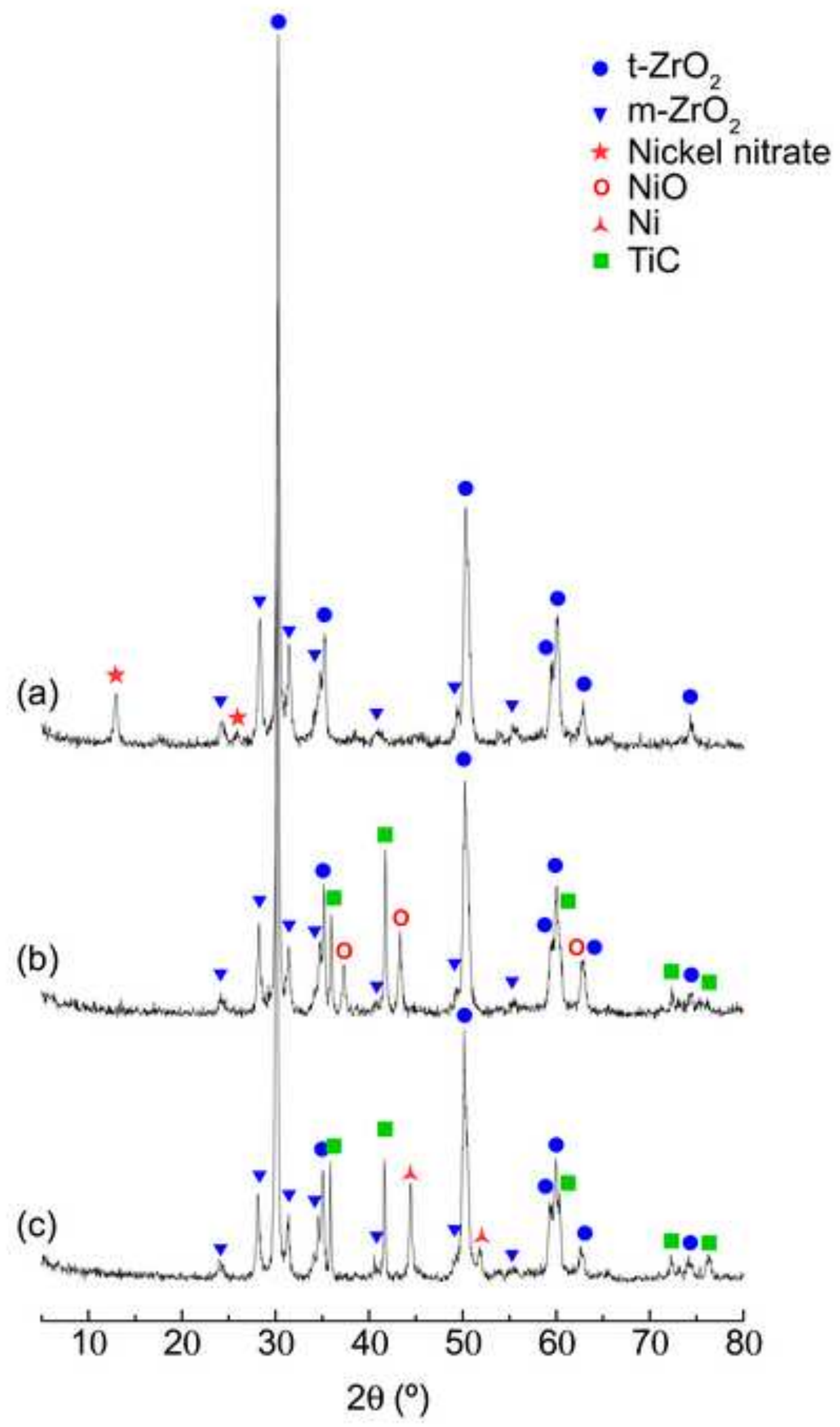


Figure 2

Click here to download high resolution image

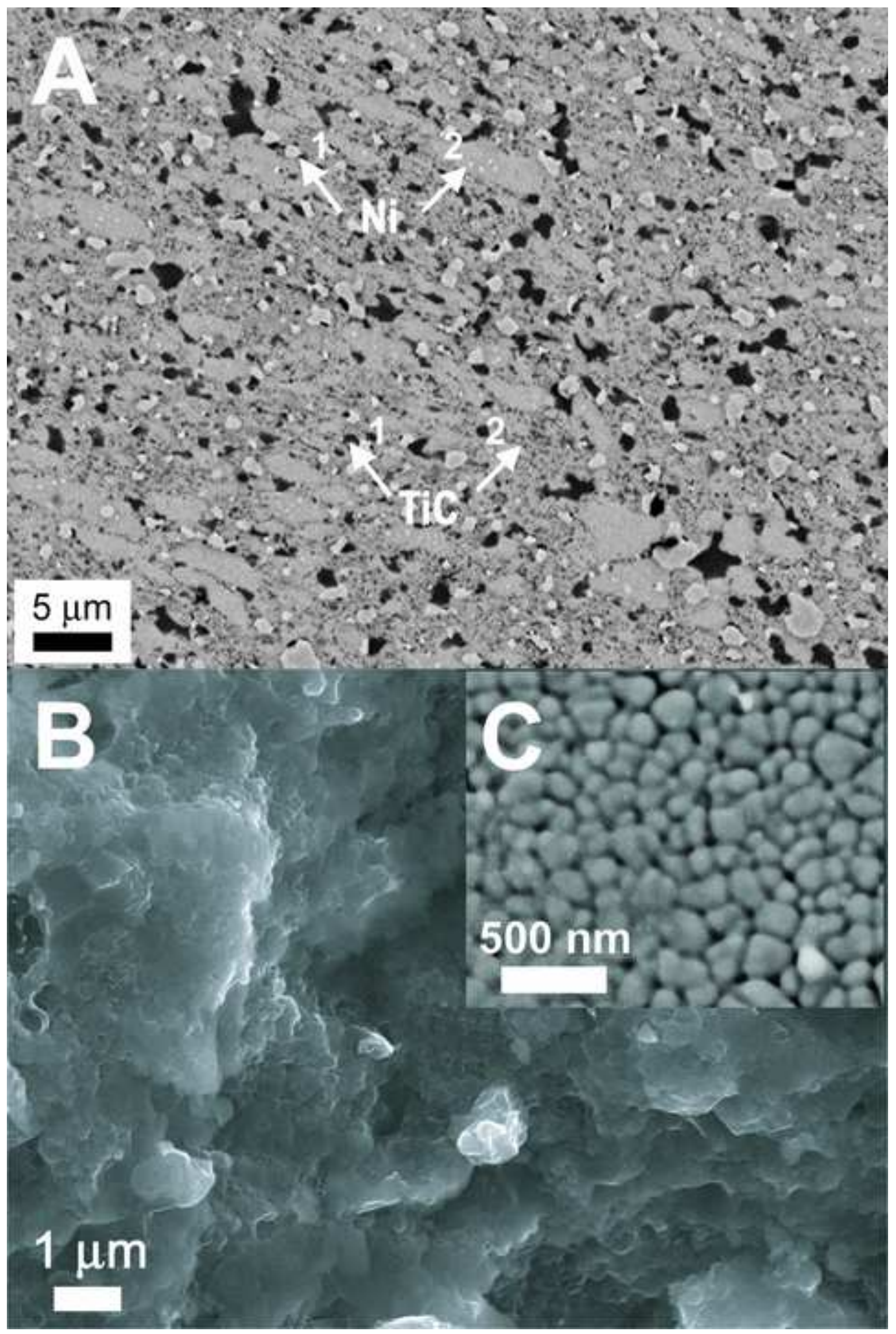


Click here to download high resolution image
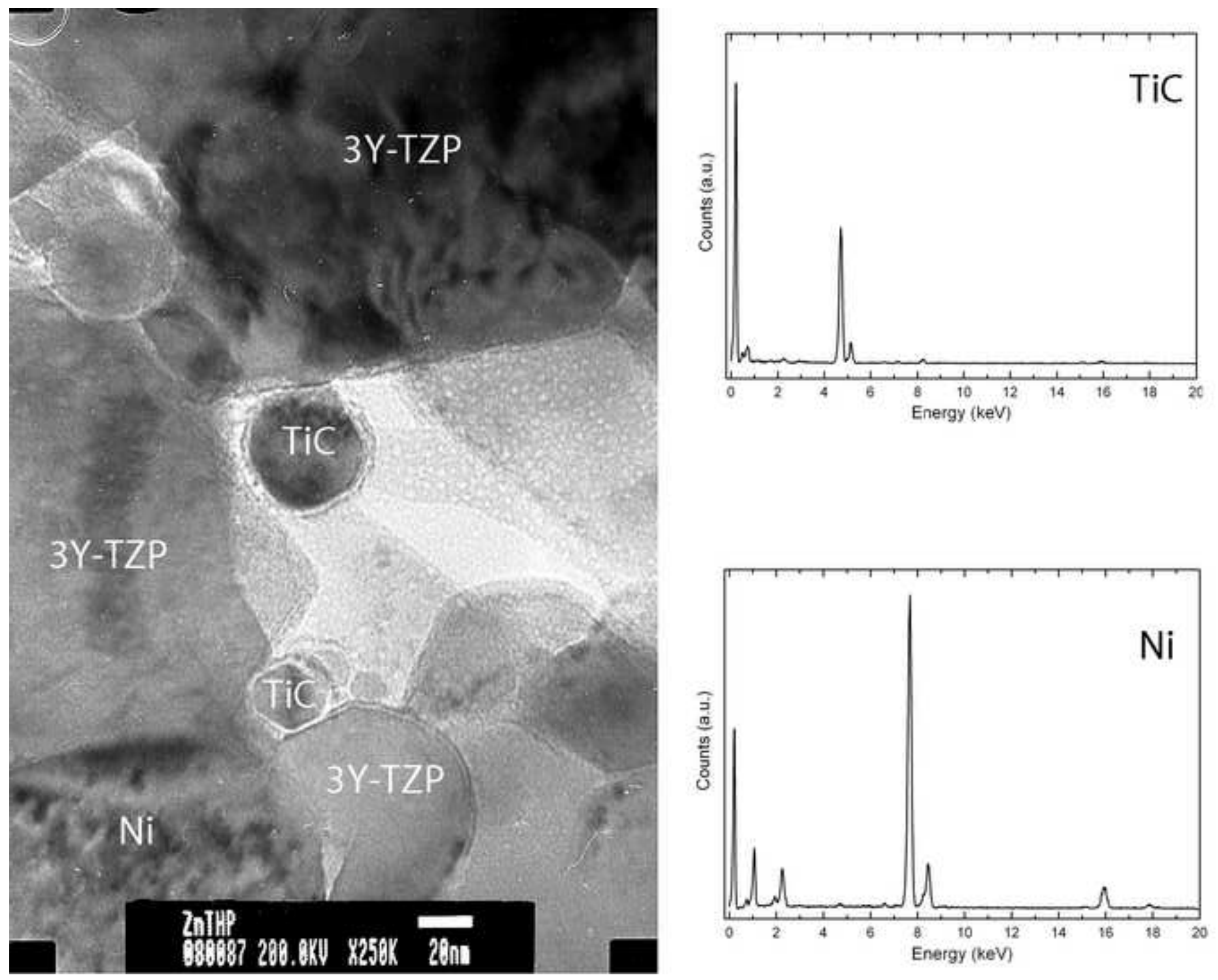


\section{A}
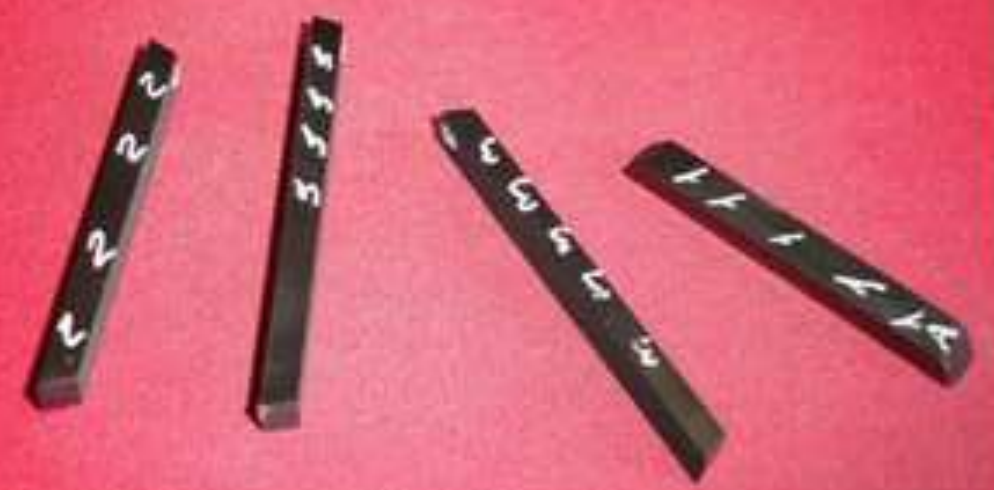

$10 \mathrm{~mm}$

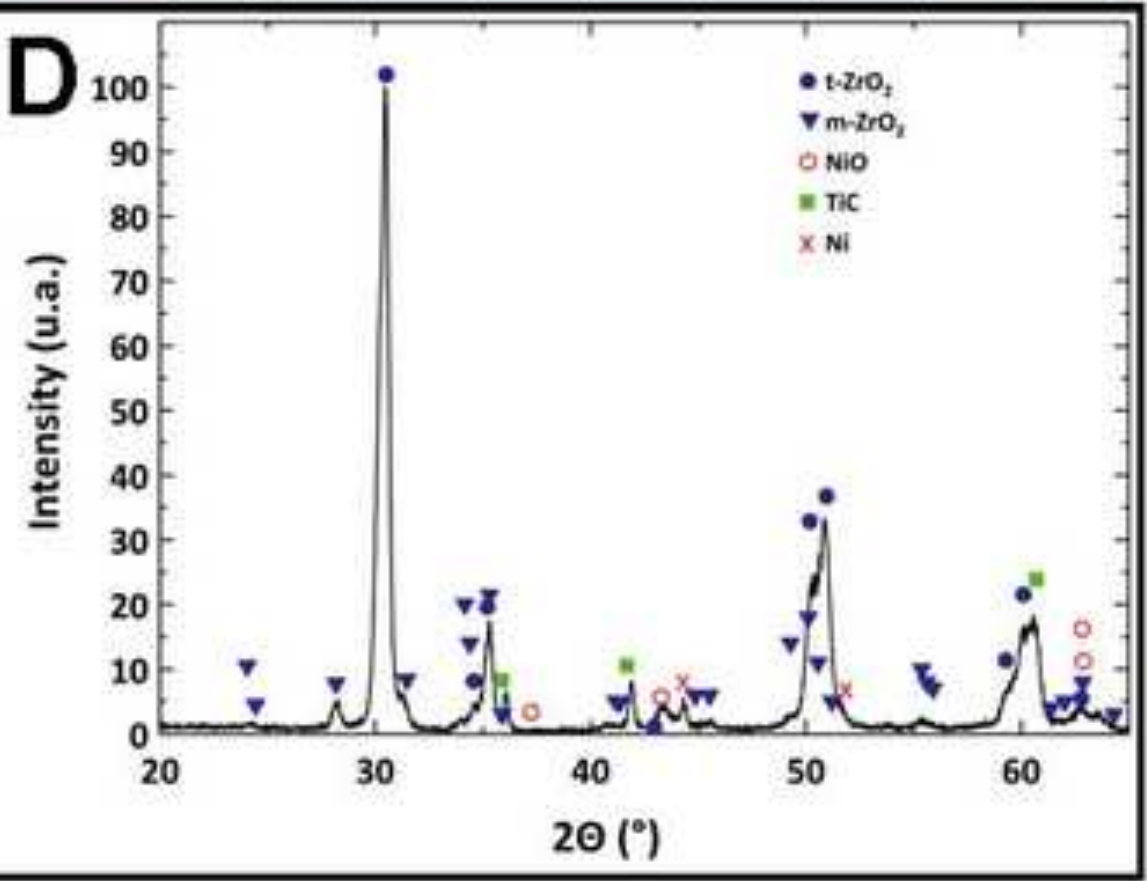

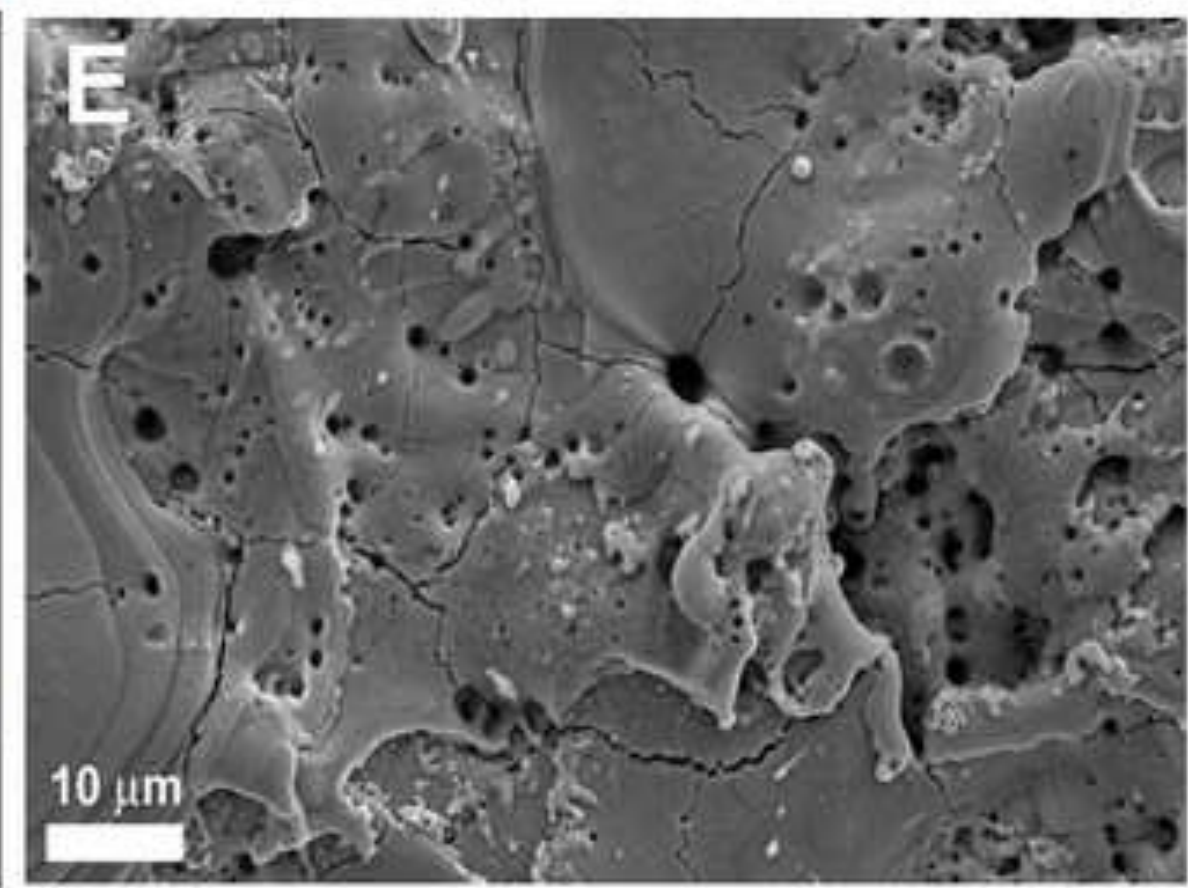

\section{c}
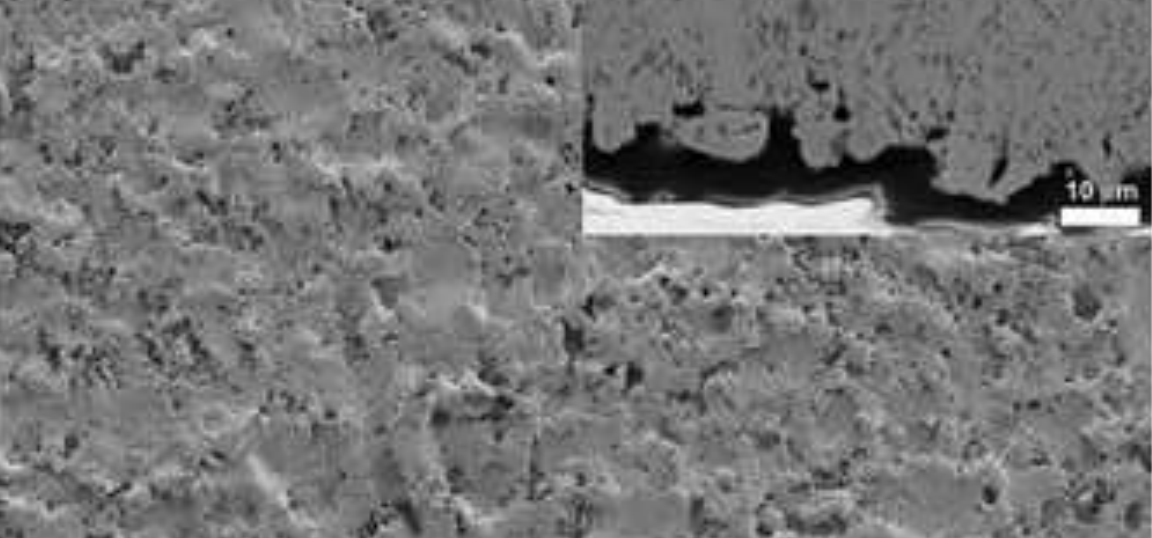

2isin:

100 ums
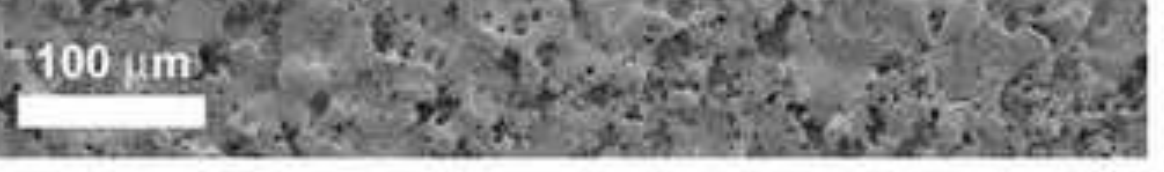


\begin{tabular}{|c|c|c|c|c|c|c|c|}
\hline Symbol & Material & $\begin{array}{c}\text { Measured } \\
\text { density } \\
\left(\mathrm{g} / \mathrm{cm}^{3}\right) \\
\end{array}$ & $\begin{array}{c}\text { Relative } \\
\text { density } \\
(\%)\end{array}$ & $\begin{array}{c}\text { Vickers } \\
\text { hardness } \\
\text { (GPa) }\end{array}$ & $\begin{array}{r}\text { Toughness } \\
\left(\mathrm{MPa} \cdot \mathbf{m}^{1 / 2}\right) \\
\end{array}$ & $\begin{array}{c}\text { Flexural } \\
\text { strength } \\
(\mathrm{MPa}) \\
\end{array}$ & $\begin{array}{l}\text { Electrical } \\
\text { resistivity } \\
(\Omega \cdot \mathrm{cm}) \cdot 10^{-4} \\
\end{array}$ \\
\hline $\mathbf{Z}$ & 3Y-TZP & $5.99 \pm 0.2$ & $99.0 \pm 0.2$ & $11.0 \pm 0.2$ & $4.9 \pm 0.2$ & $752 \pm 16$ & --- \\
\hline ZT & $\begin{array}{l}\text { 3Y-TZP/TiC } \\
\text { (28 vol\% TiC) }\end{array}$ & $5.65 \pm 0.2$ & $98.5 \pm 0.2$ & $13.8 \pm 0.3$ & $4.5 \pm 0.2$ & $727 \pm 15$ & $14.0 \pm 1.0$ \\
\hline ZTN & $\begin{array}{l}\text { 3Y-TZP/TiC/Ni } \\
(20 \mathrm{vol} \% \mathrm{TiC}, \\
8 \text { vol\% Ni) }\end{array}$ & $6.00 \pm 0.2$ & $99.1 \pm 0.2$ & $11.5 \pm 0.2$ & $6.0 \pm 0.2$ & $804 \pm 21$ & $7.2 \pm 1.0$ \\
\hline
\end{tabular}

Table 1. Properties of hot-pressed pure zirconia and composites. 